\title{
MATRIZ DE INDICADORES DE SUSTENTABILIDADE DE COLETA SELETIVA COM UTILIZAÇÃO DO MÉTODO DELPHI
}

\author{
Matrix of sustainability indicators of selective collection with \\ use of the Delphi method \\ Roberta Fechine ${ }^{1}$, Luiz Roberto Santos Moraes ${ }^{2}$
}

Recebido em 14 de maio de 2015; recebido para revisão em 03 de junho de 2015; aceito em 09 de julho de 2015; disponível on-line em 20 de julho de 2015.

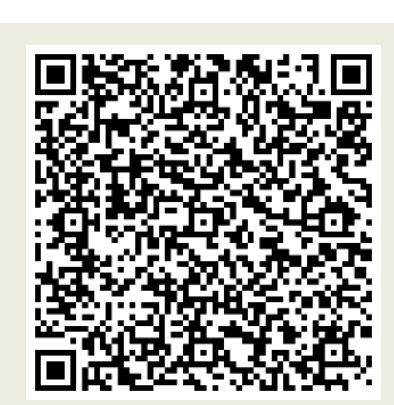

PALAVRAS CHAVE:

Resíduos sólidos urbanos;

Coleta seletiva;

Indicadores de sustentabilidade;

Método Delphi.

\section{KEYWORDS:}

Urban solid wastes;

Selective collection;

Sustainability indicators;

Delphi method.

\section{* Contato com os autores:}

${ }^{1}$ e-mail : robertafechine@gmail.com ( R. Fechine )

M.Sc em Meio Ambiente, Águas e Saneamento, Universidade Federal da Bahia-Escola Politécnica.

2e-mail : moraes@ufba.br (L.R.S.Moraes )

PhD em Saúde Ambiental, Professor Titular em Saneamento e Participante Especial, Universidade Federal da Bahia-Escola Politécnica.

\section{INTRODUÇÃO}

A Política Nacional de Resíduos Sólidos, Lei no 12.305/2010, traz entre seus objetivos a não geração, redução, reutilização, reciclagem, tratamento dos resíduos sólidos e disposição ambientalmente adequada dos rejeitos. Nesta ordem de prioridade a coleta seletiva tem papel fundamental na nova política brasileira. Esta prática estimula a reutilização e a reciclagem, além 
de promover a inclusão social e econômica dos catadores de materiais reutilizáveis e recicláveis. $\mathrm{O}$ Decreto regulamentador da PNRS ( $n$ o 7.404/2010) deixa claro que a coleta seletiva é um instrumento essencial para se atingir a meta da disposição final ambientalmente adequada dos rejeitos.

Apesar da importância, a prática brasileira da coleta seletiva ainda é incipiente frente à quantidade crescente de resíduos sólidos urbanos. Dados da Pesquisa Nacional de Saneamento Básico 2008 revelam que apenas 18\% dos municípios brasileiros operam algum programa de coleta seletiva (IBGE, 2010). As Administrações Municipais enfrentam problemas de ordem técnica e econômica para expandir a coleta seletiva de forma universalizada.

A formulação de programas de coleta seletiva muitas vezes é marcada pela falta de objetividade, eficiência, controle e monitorização. A importância da sustentabilidade destes programas é justificável pelo fato de maior parte dos municípios brasileiros não possuir programas efetivos, além de a coleta seletiva desviar os resíduos sólidos dos aterros sanitários, aumentando sua vida útil.

Os indicadores de sustentabilidade podem ser entendidos como lentes capazes de enxergar os pontos positivos, pontos frágeis e problemas que acabam inviabilizando o programa. Neste cenário, com a aplicação da matriz de indicadores de sustentabilidade, problemas relacionados à gestão, ao planejamento e ao gerenciamento da coleta seletiva poderão ser detectados, podendo auxiliar na monitorização dos programas, propor metas e alternativas que ampliem e fortaleçam as ações de coleta seletiva, além de permitir o controle social a ser exercido pela população.

\section{OBJETIVO}

O objetivo geral consiste em estabelecer uma matriz de indicadores capaz de avaliar o grau de sustentabilidade de programas de coleta seletiva de resíduos sólidos urbanos utilizando o método Delphi. Para alcançá-lo têm-se os seguintes objetivos específicos: identificar os principais indicadores de sustentabilidade utilizados nos programas de coleta seletiva existentes no País; selecionar e validar indicadores de referência e compor a matriz de indicadores de sustentabilidade de coleta seletiva (MISCS).

\section{REVISÃO BIBLIOGRÁFICA: UMA BREVE ABORDAGEM CONCEITUAL}

A coleta seletiva é uma das atividades inseridas no conceito da gestão integrada e compartilhada de resíduos sólidos urbanos, configurando uma visão mais ampla da problemática dos resíduos (RIBEIRO, 2009). A amplitude se dá, principalmente, na maior participação de atores e na inclusão de catadores de materiais reutilizáveis e recicláveis, abrangendo, além de variáveis ambientais, variáveis econômicas e sociais.

É comum os termos reciclar, reutilizar e reaproveitar se confundirem. As atividades de separar, coletar e reciclar estão associadas, mas não estão necessariamente dependentes entre si. Os termos reciclagem e reutilização são definidos na PNRS em seu Art.3ㅇ da seguinte forma:

XIV - reciclagem: processo de transformação dos resíduos sólidos que envolve a alteração de suas propriedades físicas, físico-químicas ou biológicas, com vistas à transformação em insumos ou novos produtos...

XVIII - reutilização: processo de aproveitamento dos resíduos sólidos sem sua transformação biológica, física ou físico-química... (BRASIL, 2010, p.2, grifo nosso).

$\mathrm{Na}$ ordem de prioridade de objetivos estabelecida pela PNRS, ou seja, não geração, redução, reutilização, reciclagem, tratamento dos resíduos e disposição ambientalmente adequada dos rejeitos, a coleta seletiva tem papel importante na reciclagem e reutilização.

A Lei $n$ o 12.305/2010 define coleta seletiva: coleta de resíduos sólidos previamente segregados conforme sua constituição ou composição (Art.3ำ, inciso V). À luz da Lei a separação na fonte geradora é uma atividade preliminar à coleta seletiva que se resume ao transporte do material já separado. Para um resultado satisfatório, fica claro que não é 
suficiente apenas separar os resíduos, devendo existir um sistema de coleta eficiente. Dessa forma, a coleta seletiva pode ser entendida como o processo de coleta de resíduos sólidos urbanos previamente separados na fonte geradora e destinados à sua reutilização e reciclagem.

Os primeiros programas de coleta seletiva, visando à reciclagem de resíduos sólidos no Brasil começaram a ser implantados a partir da década de 1980 como alternativas inovadoras para a redução da geração de resíduos sólidos. A experiência pioneira ocorreu em 1985 na cidade de Niterói-RJ. Com pouco mais de 30 anos desde a primeira implantação, a coleta seletiva de resíduos sólidos urbanos ainda contribui pouco com a quantidade de resíduos recuperados. O Instituto de Pesquisa Econômica Aplicada (IPEA) publicou no Comunicado $145^{1}$ uma estimativa da participação dos programas de coleta seletiva formal que atingem apenas $4,1 \%$ de material recuperado (Tabela 1).

A maior visibilidade da questão ambiental e a incorporação do conceito de sustentabilidade trouxe a preocupação com a geração de resíduos. A questão dos resíduos sólidos urbanos aborda diversas dimensões (ambiental, social, econômica) e, portanto, necessita de indicadores que permitam a monitorização e a avaliação da sustentabilidade associada à gestão de resíduos sólidos, em particular, a coleta seletiva. Para Lozano (2012) o que difere os indicadores de sustentabilidade de outros indicadores é que a função deles é medir a capacidade de um sistema de se adaptar a mudanças e exigir uma visão integrada de mundo, relacionando diferentes dimensões de uma dada comunidade.

Para Santiago e Dias (2012) a gestão de resíduos sólidos urbanos deve ser continuamente avaliada por meio de indicadores de sustentabilidade, tornando-se instrumento importante para os gestores públicos avaliarem e monitorizarem a sustentabilidade, bem como planejarem estratégias.

No Brasil, são encontradas bases públicas de dados oficiais, como as do IBGE e do Ministério das Cidades, que contemplam indicadores de coleta seletiva. Desde dezembro de 2012, os gestores podem contar com mais uma base de informações pública. Atendendo a PNRS (BRASIL, 2010), foi implantado o Sistema Nacional de Informações sobre Gestão de Resíduos Sólidos (SINIR) que apresenta estatísticas e indicadores sobre os serviços públicos e privados de gestão de resíduos disponibilizados pelo Sistema Nacional de Informações sobre Saneamento (SNIS). Atualmente, o banco de dados do SINIR disponibiliza 45 indicadores sobre resíduos sólidos urbanos entre os anos de 2002 a 2010. Para o caso específico da coleta seletiva, o SINIR disponibiliza quatro indicadores:

- taxa de recuperação de recicláveis em relação à quantidade de resíduos domiciliares (RDO) e resíduos públicos (RPU) (\%);

- massa recuperada per capita (kg/hab.dia);

- relação entre quantidades da coleta seletiva e RDO (\%);

- massa per capita recolhida via coleta seletiva (kg/hab.ano).

\begin{tabular}{|l|c|c|c|}
\hline \multicolumn{4}{|c|}{ TABELA 1: Estimativa da participação da coleta seletiva formal (2008). } \\
\hline Resíduos & $\begin{array}{c}\text { Resíduos reciclados } \\
\text { (mil t/ano) }\end{array}$ & $\begin{array}{c}\text { Quantidade recuperada } \\
\text { (mil t/ano) }\end{array}$ & $\begin{array}{c}\text { Participação da coleta } \\
\text { seletiva (\%) }\end{array}$ \\
\hline Metais & $9.817,8$ & 72,3 & 0,7 \\
\hline Papel/papelão & $3.827,9$ & 285,7 & 7,5 \\
\hline Plástico & 962,0 & 170,3 & 17,7 \\
\hline Vidro & 489,0 & 50,9 & 10,4 \\
\hline Total & $14.134,7$ & 579,2 & 4,1 \\
\hline
\end{tabular}

\footnotetext{
${ }^{1}$ Comunicado 145 - Plano Nacional de Resíduos Sólidos: diagnóstico dos resíduos urbanos, agrosilvopastoris e a questão dos catadores. Brasília, 2012.
} 
Em termos de produção científica desenvolvida sobre essa temática, destacam-se vários trabalhos que mostram a importância da monitorização dos programas de coleta seletiva. A Tabela 2 apresenta uma lista de vários trabalhos sobre indicadores específicos para coleta seletiva.

De uma maneira geral, os municípios brasileiros carecem de gerenciamento e gestão de resíduos sólidos, o que influencia, direta e negativamente, a prática da coleta seletiva sustentável. Assim, a pesquisa foi desenvolvida para auxiliar na gestão através da matriz de indicadores de sustentabilidade.

\section{METODOLOGIA}

A pesquisa foi iniciada com a revisão bibliográfica em bases públicas e literatura acadêmica sobre os indicadores de sustentabilidade de coleta seletiva de resíduos sólidos urbanos. Foram consultados artigos científicos, periódicos, dissertações, teses, legislações e livros. O número de indicadores encontrados foi significativo. Dessa forma, objetivando reduzir esse número e tornar a lista de referência menos extensa, optou-se por considerar indicadores semelhantes com apenas um indicador e trabalhar com os mais utilizados e aplicados em pesquisas e estudos de caso. Os indicadores foram agrupados em dimensões da sustentabilidade (institucional/operacional, econômica, ambiental e sociocultural) relacionados a princípios, conforme indicado por diversos autores.

A matriz preliminar foi composta por quatro dimensões da sustentabilidade, 24 indicadores e 72 tendências. Na matriz, é apresentada a forma de apuração de cada indicador, e cada tendência foi avaliada pelo painelista com a atribuição de notas na escala de 1 a 5 , ou seja, quanto maior a nota, maior seria a sustentabilidade do indicador.

As faixas utilizadas para a avaliação das tendências à sustentabilidade dos indicadores foram baseadas em diversos autores e bases públicas de indicadores, sendo importante destacar que os valores de referência para as tendências devem passar por atualizações contínuas para garantir a sua aplicabilidade.

Assim, a estrutura da matriz preliminar de indicadores de sustentabilidade de coleta seletiva pode ser observada na Tabela 3.

\begin{tabular}{|c|c|c|}
\hline \multicolumn{2}{|c|}{ TABELA 2: Trabalhos sobre indicadores específicos para coleta seletiva. } \\
\hline Fonte & $\begin{array}{c}\text { No de indicadores } \\
\text { identificados }\end{array}$ & Estudo realizado \\
\hline Campos (1994) & 17 & Reavaliação do gerenciamento da coleta seletiva de RSD \\
\hline Aguiar (1999) & 19 & Parcerias em programas de coleta seletiva de RSD \\
\hline Milanez (2002) & 16 & Aspecto operacional de coleta seletiva - Vitória (ES) \\
\hline Bringhenti (2004) & 6 & Avaliação dos progressos da coleta seletiva - Londrina (PR) \\
\hline Lima (2006) & 23 & Coleta seletiva com inclusão social - pesquisa COSELIX (SP) \\
\hline Ribeiro (2009) & 18 & Índice para avaliação do desempenho da coleta seletiva (SP) \\
\hline Kovacs et al. & 31 & Indicadores e índices de sustentabilidade para coleta seletiva e \\
(2010) & 18 & Conganizações de catadores (SP) \\
\hline Besen (2011) & 3 & Análise da sustentabilidade do projeto Cata Renda - Cruz das Almas (BA) \\
\hline Santiago (2011) & 4 & Indicadores sócio ambientais - São Leopoldo (RS) \\
\hline Duarte (2012) & 16 &
\end{tabular}




\begin{tabular}{|c|c|c|c|c|c|}
\hline \multicolumn{3}{|c|}{$\begin{array}{c}\text { Indicadores e Dimensões da } \\
\text { Sustentabilidade }\end{array}$} & Forma de apuração & $\begin{array}{c}\text { Tendência à } \\
\text { Sustentabilidade }\end{array}$ & Nota \\
\hline \multirow{3}{*}{ 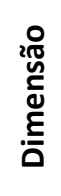 } & \multirow{3}{*}{ Ind.01 } & \multirow{3}{*}{ descrição do indicador } & & tendência 01 & \\
\hline & & & & tendência 02 & \\
\hline & & & & tendência 03 & \\
\hline
\end{tabular}

FONTE: Fechine (2014).

Definida a matriz preliminar, partiu-se para a composição de painel de especialistas, sendo considerados especialistas os profissionais que atuam na área acadêmica, no planejamento e gestão de resíduos sólidos urbanos e na operação das atividades relacionadas à coleta seletiva. "Quando falamos aqui de especialistas, não estamos nos referindo necessariamente a títulos" (MINAYO, 2009, p. 88). Essa interação de experiências acumuladas colaborou com a definição da MISCS. A seleção foi realizada por meio de busca na Plataforma Lattes, consulta a entidades de planejamento e gestão de resíduos sólidos urbanos, cooperativas de reciclagem e indicação de pesquisadores.

O painel inicial foi composto por 50 especialistas. A validação externa da matriz pelos especialistas foi realizada por meio do método Delphi, que busca o consenso de opiniões, sendo geralmente realizadas duas ou três rodadas de aplicação até que um consenso ou quase consenso seja obtido. Após uma breve revisão da literatura, Santiago (2011) mostrou que os níveis de consenso podem variar entre 50 e $80 \%$. Para Scarparo et al. (2012) o nível de consenso é tarefa reservada ao pesquisador e não há uma regra pré-determinada para estabelecê-lo.

Nesta pesquisa, foram realizadas duas rodadas, sendo que o nível de consenso adotado foi de 50\%. Para a 1a rodada de aplicação do Delphi foi utilizada a distribuição de frequência absoluta de respostas, ou seja, a tendência que obtiver uma frequência de resposta (f) igual ou superior a $50 \%$ (NC_50) será validada. Nos casos em que este parâmetro não foi atingido foi realizada uma nova rodada. Na 2a rodada, quando a tendência não atingiu o NC proposto, foi considerada a pontuação com maior frequência dentre todas as outras, para então, o consenso final ser determinado.

Após um pré-teste, cujo objetivo foi a verificação da viabilidade da plataforma eletrônica escolhida para a aplicação do Delphi, foi enviado email aos painelistas com o link de acesso ao questionário na plataforma eletrônica Survs ${ }^{\circledR}$. Durante o preenchimento do questionário, o painelista pontuava as tendências à sustentabilidade para cada indicador, além de contribuir com sugestões e críticas em espaço destinado. Cada tendência foi avaliada pelo painelista com a atribuição de notas na escala de 1 a 5 , ou seja, quanto maior a nota maior será a sustentabilidade do indicador. Considerou-se que cada dimensão deve ter igual importância para a sustentabilidade da coleta seletiva, não sendo, portanto, atribuídos pesos a elas. No questionário os indicadores estão organizados em dimensões, conforme Figura 1.

A primeira rodada procurou estabelecer o primeiro consenso de opiniões acerca dos indicadores de sustentabilidade e coleta seletiva e o aprimoramento e detalhamento dos indicadores propostos. Após o término da rodada, os resultados foram analisados para verificar o nível de consenso dos painelistas. Aqueles indicadores que não alcançaram o nível de consenso proposto (NC $\geq 50 \%$ ), juntamente com algumas sugestões feitas pelos painelistas, prosseguiram para mais uma rodada da pesquisa. A segunda rodada teve como objetivo o feedback da 1 1 a rodada para os painelistas e a busca do consenso final. O consenso final também utilizou o NC proposto que, quando não atingido, foi considerada a pontuação com maior frequência dentre todas. 


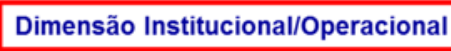

Ind.01 - Gestão compartilhada

Forma e apuração: existência de participação da sociedade civil

\begin{tabular}{l|ccccc} 
& 1 & 2 & 3 & 4 & 5 \\
\hline existe e funciona & $\bigcirc$ & $\bigcirc$ & $\bigcirc$ & $\bigcirc$ & $\bigcirc$ \\
\hline existe, mas não funciona & $\bigcirc$ & $\bigcirc$ & $\bigcirc$ & $\bigcirc$ & $\bigcirc$ \\
\hline não existe & $\bigcirc$ & $\bigcirc$ & $\bigcirc$ & $\bigcirc$ & $\bigcirc$ \\
\cline { 1 - 2 } Nota: Indicador proposto por Besen (2011) & & &
\end{tabular}

FIGURA 1: Fragmento do questionário na plataforma Survs enviado aos painelistas na 1’ rodada, indicando a dimensão, o indicador (Ind.01), sua forma de apuração e a escala de pontuação às tendências.

FONTE: Fechine (2014).

Após a validação da matriz pelos especialistas é possível concluir sobre o Grau de Sustentabilidade (GS) da coleta seletiva, por meio da Equação 1.

$\mathrm{GS}=\frac{\sum \text { notas da avaliaçãode campo }}{\sum \text { máxima pontuaçãoda matriz final }} \times 10 \quad$ Eq.[1]

Com base nas pesquisas de Besen (2011) e Santiago (2011), o grau de sustentabilidade (GS) se situa em uma das faixas mostradas na Tabela 4.

\section{RESULTADOS}

\subsection{MATRIZ PRELIMINAR DE INDICADORES DE SUSTENTABILIDADE DE COLETA SELETIVA}

Após a revisão bibliográfica crítica realizada sobre as bases públicas e a bibliografia acadêmica sobre os indicadores de sustentabilidade específicos para a coleta seletiva, o modelo de sustentabilidade de um programa de coleta seletiva que foi adotado nesta pesquisa é definido como: conjunto de atividades capazes de garantir a efetividade do serviço atingindo resultados nas dimensões da sustentabilidade consideradas: institucional/operacional, econômica, ambiental e sociocultural.

O número de indicadores encontrados na bibliografia consultada foi significativo. Dessa forma, com o objetivo de reduzir este número e tornar matriz preliminar menos extensa, optou-se por considerar indicadores semelhantes como apenas um indicador e trabalhar com os mais utilizados e aplicados em pesquisas e estudos de caso. As dimensões utilizadas para o enquadramento desses indicadores estão relacionadas a princípios de sustentabilidade conforme observado na Tabela 5.

A matriz preliminar foi composta por 24 indicadores distribuídos em quatro dimensões, dos quais seis são da dimensão institucional/operacional, sete da dimensão econômica, cinco da dimensão ambiental e seis da dimensão sociocultural. Além disso, na matriz, são encontradas, também, para cada indicador, tendências à sustentabilidade (totalizando 72 tendências) baseadas em diversos autores e experiências de especialistas e práticas municipais. A Tabela 6 apresenta a Matriz Preliminar de Indicadores de Sustentabilidade de Coleta Seletiva que foi submetida aos painelistas na primeira rodada de aplicação do método Delphi. Ao se trabalhar com indicadores, é importante destacar que os valores de referência para as tendências devem passar por atualizações contínuas para garantir a sua aplicabilidade.

TABELA 4: Grau de Sustentabilidade da coleta seletiva.

\begin{tabular}{|c|c|}
\hline Intervalo & Grau de Sustentabilidade (GS) \\
\hline 0 a 2,5 & Insustentabilidade \\
\hline 2,6 a 5,0 & Baixa sustentabilidade \\
\hline 5,1 a 7,5 & Média sustentabilidade \\
\hline 7,6 a 10,0 & Alta sustentabilidade \\
\hline
\end{tabular}

FONTE: Adaptado de Besen (2011) e Santiago (2011). 
TABELA 5: Princípios e dimensões da sustentabilidade para coleta seletiva.

\begin{tabular}{|c|c|}
\hline Dimensão & Princípio \\
\hline Institucional/Operacional & Produtividade e eficiência do programa \\
\hline Econômica & Custos e receitas da coleta seletiva \\
\hline Ambiental & Preservação das riquezas naturais e diminuição da degradação ambiental \\
\hline Sociocultural & Inclusão socioeconômica, equidade e universalização do serviço \\
\hline
\end{tabular}

FONTE: Fechine (2014).

TABELA 6: Matriz Preliminar de indicadores de sustentabilidade de coleta seletiva.

(continua)

\begin{tabular}{|c|c|c|c|c|c|}
\hline \multicolumn{3}{|c|}{$\begin{array}{c}\begin{array}{c}\text { INDICADORES E DIMENSÕES DA } \\
\text { SUSTENTABILIDADE }\end{array} \\
\end{array}$} & FORMA DE APURAÇÃO & TENDÊNCIA À SUSTENTABILIDADE & NOTA \\
\hline \multirow{18}{*}{ 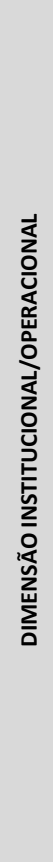 } & \multirow{3}{*}{ Ind.01 } & \multirow{3}{*}{$\begin{array}{l}\text { Gestão compartilhada (BESEN, } \\
\text { 2011) }\end{array}$} & \multirow{3}{*}{ existência de participação da sociedade civil } & - existe e funciona & \\
\hline & & & & - existe, mas não funciona & \\
\hline & & & & • não existe & \\
\hline & \multirow{3}{*}{ Ind.02 } & \multirow{3}{*}{ Marco legal no município } & \multirow{3}{*}{$\begin{array}{c}\text { existência Plano Municipal de Gestão } \\
\text { Integrada de Resíduos Sólidos que contemple } \\
\text { a coleta seletiva }\end{array}$} & - em processo de elaboração & \\
\hline & & & & - em processo de implantação & \\
\hline & & & & - não possui & \\
\hline & \multirow{3}{*}{ Ind.03 } & \multirow{3}{*}{$\begin{array}{l}\text { Instrumentos legais na relação } \\
\text { com as organizações de } \\
\text { catadores (BESEN,2011) }\end{array}$} & \multirow{3}{*}{$\begin{array}{c}\text { atendimento aos requisitos legais de } \\
\text { contratação }\end{array}$} & - contrato ou convênio com remuneração & \\
\hline & & & & - convênio sem remuneração & \\
\hline & & & & - inexistência de ambos & \\
\hline & \multirow{3}{*}{ Ind.04 } & \multirow{3}{*}{$\begin{array}{l}\text { Percentual de pessoas atendidas } \\
\text { pela CS (MILANEZ, 2002; } \\
\text { BRINGHENTI, 2004; BESEN, 2011) }\end{array}$} & \multirow{3}{*}{$\begin{array}{l}\text { ( } \mathrm{n} \text { - de habitantes atendidos pela coleta } \\
\text { seletiva)/( } \mathrm{n} \text { o total de habitantes) } \times 100\end{array}$} & - 80 a $100 \%$ & \\
\hline & & & & - 40,1 a $79,9 \%$ & \\
\hline & & & & - $-\leq 40 \%$ & \\
\hline & \multirow{3}{*}{ Ind.05 } & \multirow{3}{*}{$\begin{array}{l}\text { Área de abrangência do serviço } \\
\text { de coleta seletiva (IBGE, PNSB) }\end{array}$} & \multirow{3}{*}{$\begin{array}{c}\text { qual a abrangência da coleta seletiva no } \\
\text { município }\end{array}$} & - todo município & \\
\hline & & & & - área urbana & \\
\hline & & & & $\begin{array}{l}\text { - exclusivamente em alguns bairros da área } \\
\text { urbana }\end{array}$ & \\
\hline & \multirow{3}{*}{ Ind.06 } & \multirow{3}{*}{$\begin{array}{l}\text { Parcerias entre as organizações } \\
\text { (RIBEIRO et. al., 2009) }\end{array}$} & \multirow{3}{*}{$\begin{array}{l}\text { quantidade de parcerias entre as } \\
\text { organizações }\end{array}$} & - 80 a $100 \%$ & \\
\hline & & & & - 50,1 a $80 \%$ & \\
\hline & & & & - $\leq 50 \%$ & \\
\hline
\end{tabular}

\begin{tabular}{|c|c|c|c|c|c|}
\hline & INDIC & $\begin{array}{l}\text { ORES E DIMENSÕES DA } \\
\text { JSTENTABILIDADE }\end{array}$ & FORMA DE APURAÇÃO & TENDÊNCIA À SUSTENTABILIDADE & NOTA \\
\hline & & Custo total do programa em & & - $\leq \mathrm{R} \$ 175,00 / \mathrm{t}$ & \\
\hline & & seletivamente- $R \$ / \mathrm{t}$ & (custo total com coleta seletiva)/(quantidade & - $\mathrm{R} \$ 170,10$ a $\mathrm{R} \$ 350 / \mathrm{t}$ & \\
\hline & กाน. & $\begin{array}{l}\text { (BRINGHENTI, 2004; LIMA, 2006; } \\
\text { MILANEZ,2002; BESEN, 2011; } \\
\text { CAMPANI, 2012) }\end{array}$ & coletada pela coleta seletiva) & - $\geq \mathrm{R} \$ 350,00 / \mathrm{t}$ & \\
\hline & & Percentual de autofinanciamento & & - 80 a $100 \%$ & \\
\hline & Ind.08 & da coleta seletiva-\% & $\begin{array}{l}\text { (recursos do } 1 \text { (P) e /ou taxa)/(custo total da } \\
\text { coleta seletiva) } \times 100\end{array}$ & - 50,1 a $79,9 \%$ & \\
\hline & & (BESEN,2011) & & - $\leq 50 \%$ & \\
\hline & & Percentual custo da coleta & & - $\leq 50 \%$ & \\
\hline 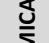 & Ind.09 & seletiva com a coleta regular e & $\begin{array}{l}\text { (custo total com coleta seletiva)/(custo da } \\
\text { coleta regular + custo com aterramento) } \times 100\end{array}$ & - 50,1 a $199,9 \%$ & \\
\hline ‘ర & & aterramento - \% (BESEN, 2011) & & - $\geq 200 \%$ & \\
\hline ¿્ఝ & & Custo da coleta seletiva em & & - $\leq 50 \%$ & \\
\hline 迹 & Ind.10 & relação ao manejo de RS-\% & manejo de resíduos sólidos) ×100 & - 50,1 a $74,9 \%$ & \\
\hline 忌 & & & & - $\geq 75 \%$ & \\
\hline$\underline{\overline{0}}$ & & Relação entre despesas com & & - $<15 \%$ & \\
\hline & Ind.11 & $\begin{array}{l}\text { coleta seletiva e despesas } \\
\text { empregadas com limpeza urbana }\end{array}$ & $\begin{array}{l}\text { (despesa com coleta seletiva)/(despesa com } \\
\text { limpeza urbana) } \times 100\end{array}$ & - 15 a $30 \%$ & \\
\hline & & & & - $>30 \%$ & \\
\hline & & Percentual do orçamento & & - $<3 \%$ & \\
\hline & Ind.12 & municipal utilizado na coleta & $\begin{array}{l}\text { orcamento municipal) } \times 100 \\
\text { orchamento para cota }\end{array}$ & - 3 a $6 \%$ & \\
\hline & & & & - $>6 \%$ & \\
\hline & & Aplicação dos recursos & & - na própria manutenção da coleta seletiva & \\
\hline & Ind.13 & provenientes da coleta seletiva & $\begin{array}{l}\text { forma de aplicaçāo dos recursos provenientes } \\
\text { da coleta seletiva }\end{array}$ & - atividades socioculturais e assistenciais & \\
\hline & & (PNSB, 2008) & & - outra destinação & \\
\hline
\end{tabular}


TABELA 6: Matriz Preliminar de indicadores de sustentabilidade de coleta seletiva.

\begin{tabular}{|c|c|c|c|c|c|}
\hline \multicolumn{3}{|c|}{$\begin{array}{l}\text { INDICADORES E DIMENSÕES DA } \\
\text { SUSTENTABILIDADE }\end{array}$} & FORMA DE APURAÇÃO & TENDÊNCIA À SUSTENTABILIDADE & NOTA \\
\hline \multirow{15}{*}{ 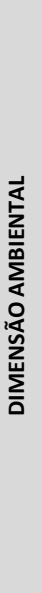 } & \multirow{3}{*}{ Ind.14 } & \multirow{3}{*}{$\begin{array}{l}\text { Massa per capita anual } \\
\text { recuperada }-\mathrm{kg} / \mathrm{hab} \text {. (SNIS, } \\
\text { 2012) }\end{array}$} & \multirow{3}{*}{ (quantidade recuperada)/(no de habitantes) } & - >15kg/hab.ano & \\
\hline & & & & - 7 a $15 \mathrm{~kg} / \mathrm{hab} . a n o$ & \\
\hline & & & & - $<7 \mathrm{~kg} /$ hab.ano & \\
\hline & \multirow{3}{*}{ Ind.15 } & \multirow{3}{*}{$\begin{array}{l}\text { Massa per capita anual coletada } \\
\text { seletivamente }-\mathrm{kg} / \mathrm{hab} . \text { ano } \\
\text { (SNIS, 2012) }\end{array}$} & \multirow{3}{*}{$\begin{array}{l}\text { (massa coletada seletivamente } 0 /(\mathrm{n} \text { - de } \\
\text { habitantes) }\end{array}$} & - $>21 \mathrm{~kg} /$ hab.ano & \\
\hline & & & & - 10 a $21 \mathrm{~kg} /$ hab.ano & \\
\hline & & & & - <10kg/hab.ano & \\
\hline & \multirow{3}{*}{ Ind.16 } & \multirow{3}{*}{$\begin{array}{l}\text { Taxa de rejeitos - \% (LIMA, 2006; } \\
\text { BESEN, 2011; DUARTE, 2012) }\end{array}$} & \multirow{3}{*}{$\begin{array}{l}\text { (quantidade de coleta seletiva - quantidade } \\
\text { comercializada)/(quantidade da coleta } \\
\text { seletiva) } \times 100\end{array}$} & - $\leq 10 \%$ & \\
\hline & & & & - 10,1 a $19,9 \%$ & \\
\hline & & & & - $\geq 20 \%$ & \\
\hline & \multirow{3}{*}{ Ind.17 } & \multirow{3}{*}{$\begin{array}{l}\text { Taxa de material recolhido nos } \\
\text { PEVs em relação a quantidade } \\
\text { total coletada pela coleta seletiva } \\
\text { - \% (LIMA, 2006) }\end{array}$} & \multirow{3}{*}{$\begin{array}{l}\text { (quantidade coletada nos PEVs)/(quantidade } \\
\text { coleta seletiva) } \times 100\end{array}$} & - $<20 \%$ & \\
\hline & & & & - 20 a $40 \%$ & \\
\hline & & & & - $>40 \%$ & \\
\hline & \multirow{3}{*}{ Ind.18 } & \multirow{3}{*}{$\begin{array}{l}\text { Taxa de recuperação de } \\
\text { materiais recicláveis em relação } \\
\text { à quantidade total coletada pela } \\
\text { coleta seletiva - \% (LIMA,2006) }\end{array}$} & \multirow{3}{*}{$\begin{array}{l}\text { (quantidade coleta seletiva - quantidade de } \\
\text { rejeitos)/(quantidade coleta seletiva + } \\
\text { quantidade coleta regular)×100 }\end{array}$} & - >11\% & \\
\hline & & & & - 5,1 a $10 \%$ & \\
\hline & & & & - Até $5 \%$ & \\
\hline
\end{tabular}

\begin{tabular}{|c|c|c|c|c|c|}
\hline \multicolumn{3}{|c|}{$\begin{array}{c}\text { INDICADORES E DIMENSÕES DA } \\
\text { SUSTENTABILIDADE }\end{array}$} & FORMA DE APURAÇÃO & TENDÊNCIA À SUSTENTABILIDADE & NOTA \\
\hline \multirow{18}{*}{ 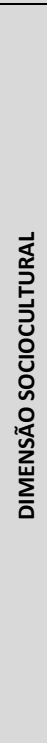 } & \multirow{3}{*}{ Ind.19 } & \multirow{3}{*}{$\begin{array}{l}\text { Adesão da população- \% (BESEN, } \\
\text { 2011; LIMA,2006; DUARTE,2012) }\end{array}$} & \multirow{3}{*}{$\begin{array}{c}\text { ( } \mathrm{n} \text { - de residências que participa do } \\
\text { programa)/(no de residências atendidas pelo } \\
\text { programa }) \times 100\end{array}$} & - $>80 \%$ & \\
\hline & & & & - 40,1 a $79,9 \%$ & \\
\hline & & & & - $\leq 40 \%$ & \\
\hline & \multirow{3}{*}{ Ind.20 } & \multirow{3}{*}{$\begin{array}{l}\text { Programas de educação e } \\
\text { divulgação - (BESEN, 2011) }\end{array}$} & \multirow{3}{*}{$\begin{array}{c}\text { frequência anual das atividades } \\
\text { desenvolvidas }\end{array}$} & - permanente, quinzenal, mansal & \\
\hline & & & & - bi ou trimestral & \\
\hline & & & & - anual ou pontual & \\
\hline & \multirow{3}{*}{ Ind.21 } & \multirow{3}{*}{$\begin{array}{l}\text { Inclusão de catadores avulsos -\% } \\
\text { (BESEN, 2011) }\end{array}$} & \multirow{3}{*}{$\begin{array}{l}\text { (no de catadores avulsos incluídos)/(no total } \\
\text { de catadores avulsos existentes) } \times 100\end{array}$} & - 80 a $100 \%$ & \\
\hline & & & & - 50,1 a $79,9 \%$ & \\
\hline & & & & - $\leq 50 \%$ & \\
\hline & \multirow{3}{*}{ Ind.22 } & \multirow{3}{*}{$\begin{array}{l}\text { Renda média mensal nas } \\
\text { cooperativas - R\$ }\end{array}$} & \multirow{3}{*}{$\begin{array}{l}\text { Valor médio pago aos catadores organizados } \\
\text { em cooperativas }\end{array}$} & - Acima de $\mathrm{R} \$ 678,00$ & \\
\hline & & & & - Entre 677,00 e $R \$ 420,00$ & \\
\hline & & & & - $<\mathrm{R} \$ 420,00$ & \\
\hline & \multirow{3}{*}{ Ind.23 } & \multirow{3}{*}{$\begin{array}{l}\text { Participação de catadores nas } \\
\text { ações de coleta seletiva (PNSB, } \\
\text { 2008) }\end{array}$} & \multirow{3}{*}{$\begin{array}{l}\text { forma de participação dos catadores nas } \\
\text { ações de coleta seletiva }\end{array}$} & $\begin{array}{l}\text { - organizados em cooperativas ou } \\
\text { associações }\end{array}$ & \\
\hline & & & & - isolada & \\
\hline & & & & - outra & \\
\hline & \multirow{3}{*}{ Ind.24 } & \multirow{3}{*}{$\begin{array}{l}\text { Existência de cooperativas ou } \\
\text { associações no município (PNSB, } \\
\text { 2008) }\end{array}$} & \multirow{3}{*}{$\begin{array}{c}\text { no de cooperativas ou associações de } \\
\text { catadores }\end{array}$} & - >18 coop. & \\
\hline & & & & - Entre 4 e 17 coop. & \\
\hline & & & & - $<3$ coop. & \\
\hline
\end{tabular}

FONTE: Fechine (2014).

\subsection{VALIDAÇÃO EXTERNA DA MATRIZ DE INDICADORES DE SUSTENTABILIDADE DE COLETA SELETIVA}

\subsubsection{Pesquisa de opinião - 1a rodada de aplicação do método Delphi}

O método Delphi possui características peculiares e demanda um cronograma de execução bem definido e o estabelecimento de prazos para o recebimento de dados confiáveis. A Figura 2 mostra o cronograma de execução do método na 1 a rodada da pesquisa.

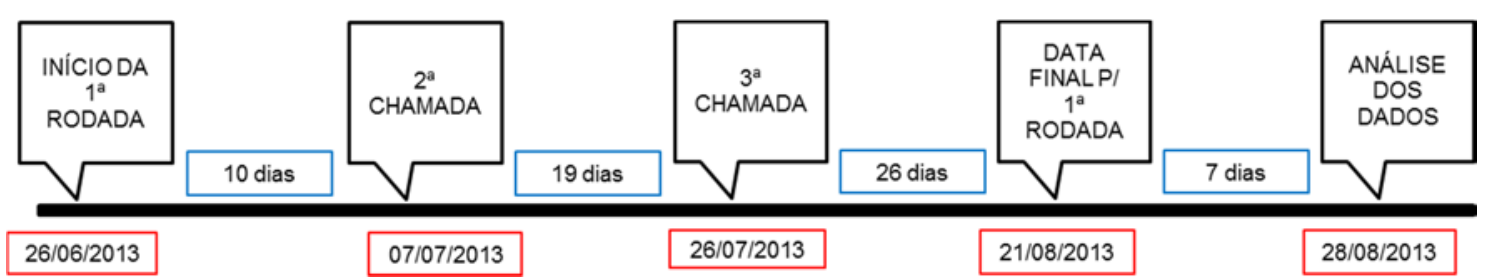

FIGURA 2: Cronograma de execução da 1a rodada de aplicação do Delphi.

FONTE: Fechine (2014) 
A 1a rodada da pesquisa teve duração de 62 dias (26/06 a 28/08/2013), incluindo a análise das respostas e a tabulação dos dados. Foram selecionados, inicialmente, 50 painelistas para a aplicação do método Delphi, sendo que 43 acusaram o recebimento e acessaram a plataforma Survs. Destes, 26 retornaram suas opiniões, representando $60,5 \%$ do total de painelistas que acusaram o recebimento do convite.

Foram avaliados 24 indicadores e suas respectivas tendências à sustentabilidade. Segundo a avaliação dos painelistas, foram atribuídas notas de 1 a 5 às tendências e àquelas em que o $N C \geq 50 \%$ foram validadas. Quando abaixo de $50 \%$, foram consideradas as sugestões e a possibilidade de ajuste para serem novamente avaliadas em rodada posterior.

O nível de consenso proposto ( $\mathrm{NC} \geq 50 \%$ ) foi atingido em $66,7 \%$ das tendências analisadas, com destaque para a dimensão sociocultural que obteve $77,8 \%$ de aceitação. Por outro lado, as dimensões econômica e ambiental apresentaram menor consenso em sua avaliação, cuja causa pode estar associada à ausência de respostas de um painelista para indicadores dessas duas dimensões. A Figura 3 apresenta a relação dos NCs para as dimensões de sustentabilidade estudadas.

Entre comentários e sugestões, foram computados 82 registros, analisados e, quando considerados pertinentes, incorporados.

Dentre as 72 tendências avaliadas na $1 \underline{a}$ rodada, $66,7 \%$ atingiram o consenso desejado nessa etapa, sendo que as demais passaram por uma nova rodada. As Tabelas 7 a 10 apresentam os resultados obtidos na 1 a rodada e indicam a frequência (f) e nível de consenso (NC) para cada tendência ( $T 1, T 2, T 3)$; para $N A$, considerar não alcançado.

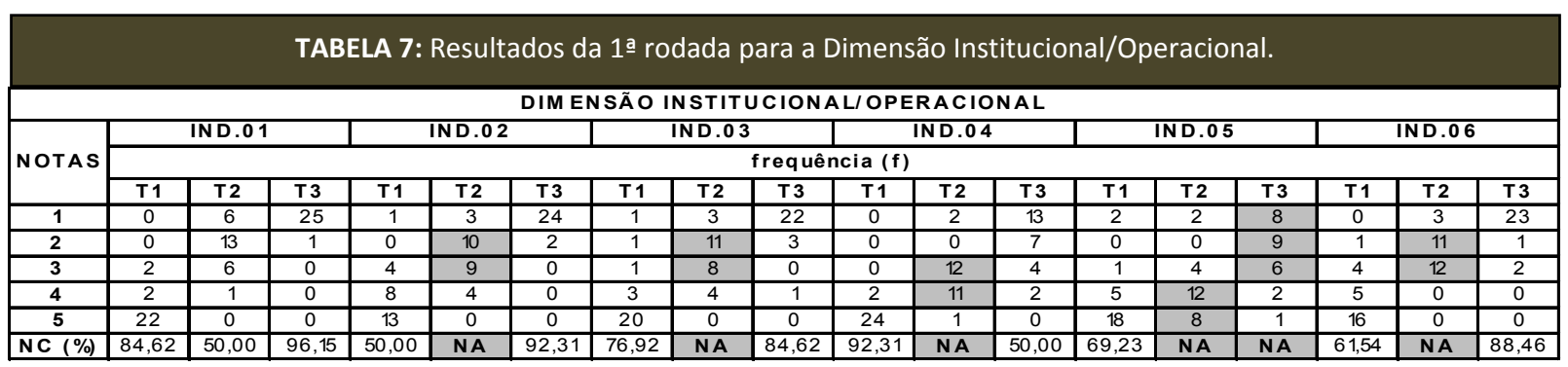

FONTE: Fechine (2014).

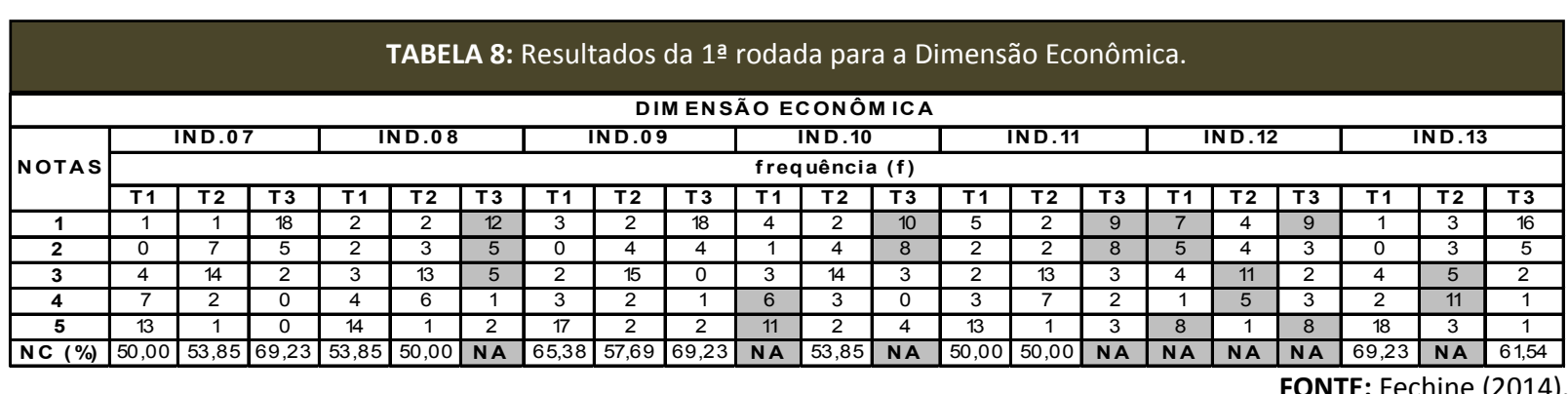

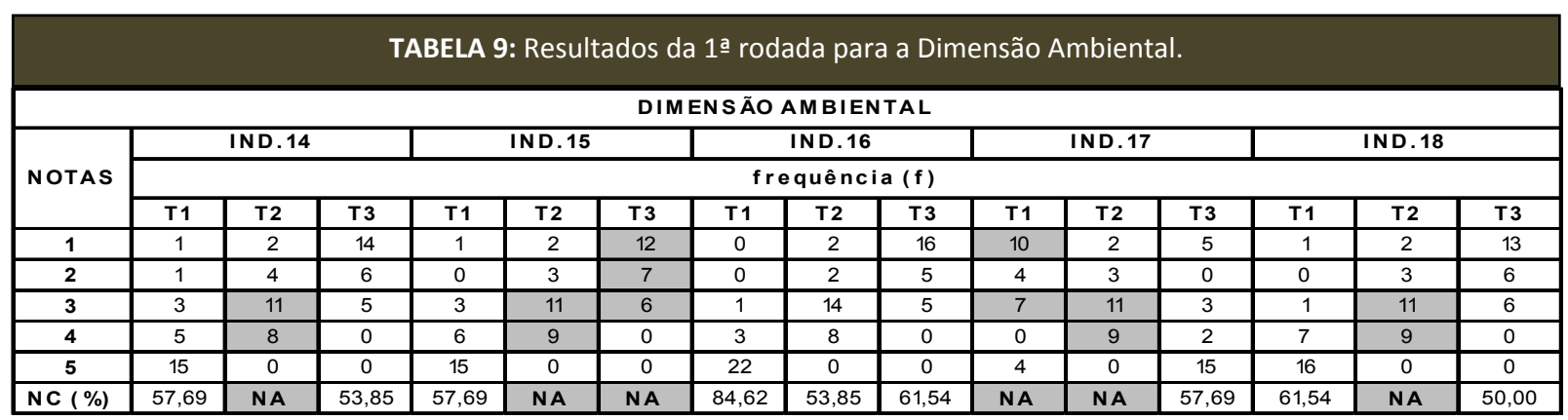




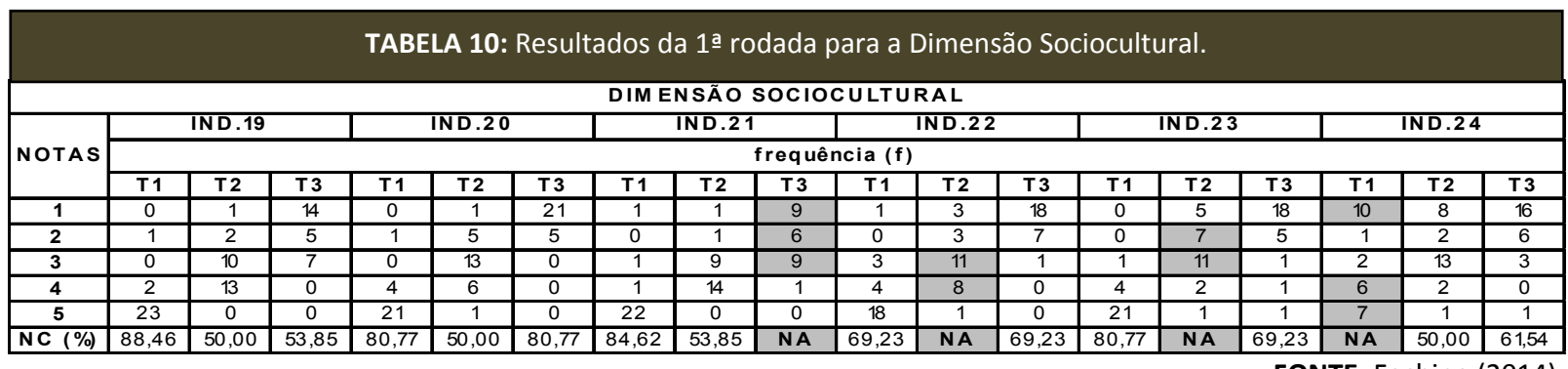

FONTE: Fechine (2014).

Observa-se na Tabela 8 que as tendências do IND.12 não atingiram o NC desejado. A análise das sugestões e comentários acerca deste indicador apontam para um indicador não muito significativo do ponto de vista da sustentabilidade, logo, para a 2a rodada este indicador foi excluído. O IND.11, apesar de atingir o consenso em duas tendências, foi questionado pelos painelistas como não sendo um dado gerencialmente utilizado. Dessa forma, o indicador foi também excluído da 2 a rodada.

Considerando as sugestões e comentários realizados pelos painelistas, alguns indicadores foram alterados para um melhor entendimento e, de uma forma geral, após a consolidação da 1a rodada Delphi houve a necessidade de alterar e incorporar algumas formas de apuração e tendências. Assim, mesmo que algumas tendências tenham sido validadas, optou-se por submeter todas elas à 2 a rodada de opiniões como forma de oportunizar ao painelista rever e reconsiderar as suas respostas.

\subsubsection{Pesquisa de opinião - 2a rodada de aplicação do método Delphi}

A segunda rodada da pesquisa teve duração de 37 dias (02 de outubro de 2013 a 08 de novembro de 2013), incluindo a análise das respostas e a tabulação dos dados. A Figura 4 mostra o cronograma de execução do método na $2^{a}$ rodada da pesquisa.

Foram convidados a participar da rodada os 26 painelistas que concluíram a 1a rodada. Destes, 25 retornaram suas opiniões, representando 96,2\% do total de painelistas convidados (Fechine, 2014). Para Wright e Giovinazzo (2000), normalmente há uma abstenção de 20 a 30\% na 2ª rodada. Nesta pesquisa a abstenção atingiu $3,8 \%$, bem abaixo da faixa considerada pelos autores.

Nesta rodada foram submetidos à avaliação dos painelistas 22 indicadores e 69 tendências. Juntamente com o novo questionário também foi apresentado um feedback dos resultados da 1 a rodada.

Na 2a rodada, semelhante à 1 a rodada, a avaliação dos painelistas também foi com a atribuição de notas às tendências na escala de $1 \mathrm{a}$ 5. O nível de consenso proposto ( $\mathrm{NC} \geq 50 \%$ ) foi atingido em $84,06 \%$ das tendências analisadas com destaque para a dimensão sociocultural que atingiu 94,44\%. A Figura 5 apresenta um comparativo entre as rodadas para cada dimensão da sustentabilidade estudada.

Após a avaliação dos painelistas apenas 11 tendências $(15,9 \%)$ não atingiram o consenso proposto ( $\mathrm{NC} \geq 50 \%$ ), indicando que nesta rodada houve um aumento da convergência de opiniões entre os painelistas.

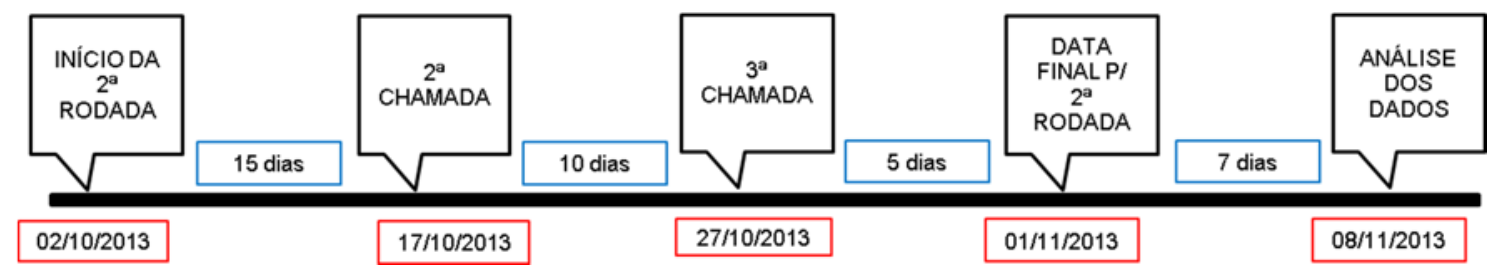

FIGURA 4: Cronograma de execução da 1ạ rodada de aplicação do Delphi. FONTE: Fechine (2014). 


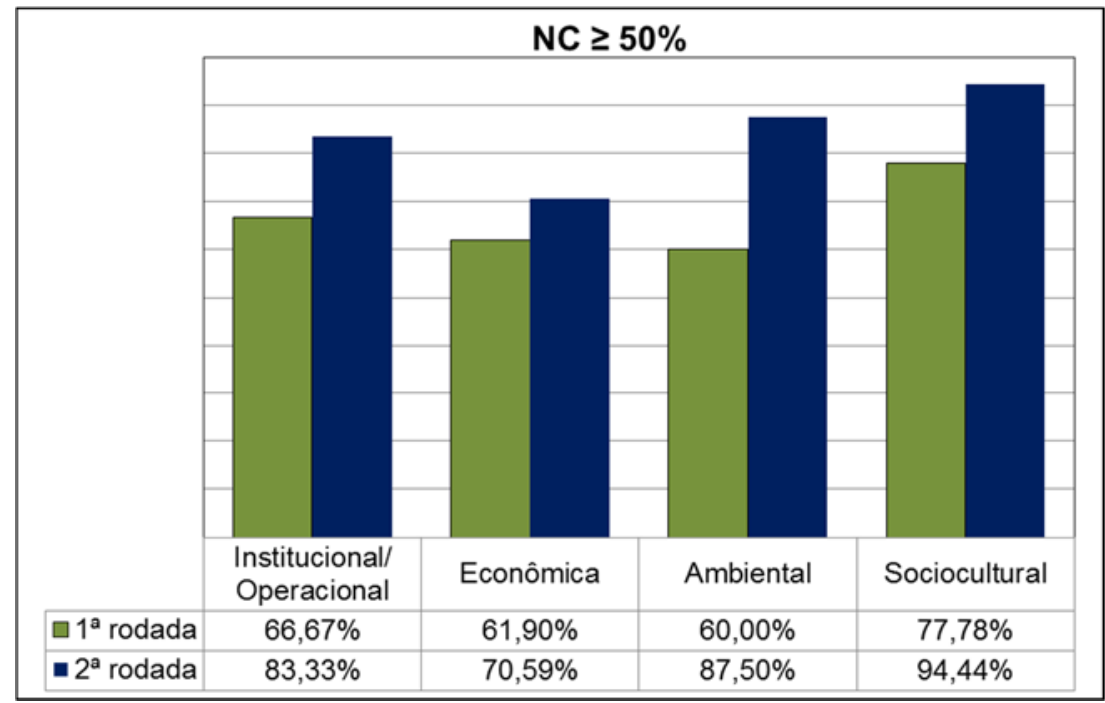

FIGURA 5: Comparativo entre o nível de consenso agrupado por dimensões. FONTE: Fechine (2014).

A 2 a rodada teve como objetivo obter o consenso final sobre a matriz de indicadores de sustentabilidade de coleta seletiva. Dessa forma, para as 11 tendências em que o NC não atingiu $50 \%$, utilizou-se como critério de consenso a pontuação com maior frequência dentre todas as outras.

\subsection{MATRIZ FINAL DE INDICADORES DE SUSTENTABILIDADE DE COLETA SELETIVA (MISCS)}

A MISCS foi construída a partir do processo de validação externa dos indicadores, das formas de apuração e tendências à sustentabilidade. Após a consolidação das rodadas foram feitas análises nos resultados das matrizes preliminares da $1 \underline{a} \mathrm{e}$ 2 a rodadas em busca da convergência das opiniões.

Dessa forma, a matriz final foi composta por 22 indicadores e 69 tendências organizados em 4 dimensões da sustentabilidade. As Tabelas 11 a 14 apresentam a matriz final de indicadores de sustentabilidade de coleta seletiva para cada dimensão adotada.

TABELA 11: Matriz final para a Dimensão Institucional/Operacional

\begin{tabular}{|c|c|c|c|c|c|}
\hline \multicolumn{3}{|c|}{ INDICADORES E DIMENSÕES DA SUSTENTABILIDADE } & FORMA DE APURAÇÃO & TENDÊNCIA À SUSTENTABILIDADE & NOTA \\
\hline \multirow{19}{*}{ 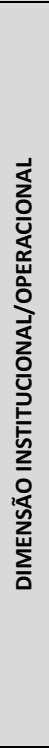 } & \multirow{3}{*}{ Ind.01 } & \multirow{3}{*}{ Gestão compartilhada } & \multirow{3}{*}{$\begin{array}{l}\text { existência de instrumentos/instâncias de } \\
\text { participação efetiva da sociedade }\end{array}$} & T1-existe e funciona & \\
\hline & & & & $\begin{array}{l}\text { T2-existe, mas não funciona ou } \\
\text { funciona de forma inadequada }\end{array}$ & \\
\hline & & & & T3-não existe & \\
\hline & \multirow{3}{*}{ Ind.02 } & \multirow{3}{*}{ Marco legal no município } & \multirow{3}{*}{$\begin{array}{c}\text { possui Plano Municipal de Gestão Integrada } \\
\text { de Resíduos Sólidos que contemple a coleta } \\
\text { seletiva? }\end{array}$} & $\begin{array}{r}\text { T1-sim, com projetos e ações propostos } \\
\text { sendo implementados }\end{array}$ & \\
\hline & & & & $\begin{array}{r}\text { T2-sim, elaborado, mas não } \\
\text { implementado ou em processo de } \\
\text { elaboração } \\
\end{array}$ & \\
\hline & & & & T3-não possui & \\
\hline & \multirow{3}{*}{ Ind.03 } & \multirow{3}{*}{$\begin{array}{l}\text { Instrumentos legais na relação com as } \\
\text { organizações de catadores }\end{array}$} & \multirow{3}{*}{$\begin{array}{c}\text { atendimento aos requisitos legais de } \\
\text { contratação }\end{array}$} & $\begin{array}{r}\text { T1-contrato ou convênio com } \\
\text { remuneração }\end{array}$ & \\
\hline & & & & T2-convênio sem remuneração & \\
\hline & & & & T3-inexistência de ambos & \\
\hline & \multirow{3}{*}{ Ind.04 } & \multirow{3}{*}{$\begin{array}{l}\text { Percentual de pessoas atendidas pela } \\
\text { coleta seletiva }\end{array}$} & \multirow{3}{*}{$\begin{array}{l}\text { ( } \mathrm{n} \text { - de habitantes urbanos atendidos pela } \\
\text { coleta seletiva)/(no total de habitantes } \\
\text { urbanos do município) } \times 100\end{array}$} & T1-80 a $100 \%$ & \\
\hline & & & & T2-40,1 a $79,9 \%$ & \\
\hline & & & & $\mathrm{T} 3-\leq 40 \%$ & \\
\hline & \multirow{3}{*}{ Ind.05 } & \multirow{3}{*}{$\begin{array}{c}\text { Área de abrangência do serviço de coleta } \\
\text { seletiva }\end{array}$} & \multirow{3}{*}{$\begin{array}{c}\text { qual a abrangência da coleta seletiva no } \\
\text { município }\end{array}$} & T1-todo município & \\
\hline & & & & T2-em toda a área urbana & \\
\hline & & & & T3-em parte da área urbana & \\
\hline & \multirow{3}{*}{ Ind.06 } & \multirow{3}{*}{ Parcerias entre as organizações } & \multirow{3}{*}{ tipo de parceria entre as organizações } & T1-apoio continuado & \\
\hline & & & & T2-orientador com prazo determinado & \\
\hline & & & & T3-assistencialista & \\
\hline & \multicolumn{4}{|c|}{ PONTUAÇÃO MÁXIMA PARA A DIMENSÃO INSTITUCIONAL/OPERACIONAL } & \\
\hline
\end{tabular}


TABELA 12: Matriz final para a Dimensão Econômica.

\begin{tabular}{|c|c|c|c|c|c|}
\hline \multicolumn{3}{|c|}{ INDICADORES E DIMENSÕES DA SUSTENTABILIDADE } & FORMA DE APURAÇÃO & TENDÊNCIA À SUSTENTABILIDADE & NOTA \\
\hline \multirow{17}{*}{ 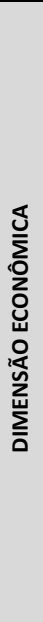 } & \multirow{3}{*}{ Ind.07 } & \multirow{3}{*}{$\begin{array}{l}\text { Custo total do programa em relação a } \\
\text { quantidade coletada seletivamente- } \mathrm{R} \$ \mathrm{t} / \mathrm{t}\end{array}$} & \multirow{3}{*}{$\begin{array}{c}\text { (custo total com coleta seletiva incluindo } \\
\text { triagem)/(quantidade coletada pela coleta } \\
\text { seletiva) }\end{array}$} & $\mathrm{T} 1-\leq \mathrm{R} \$ 250,00 / \mathrm{t}$ & \\
\hline & & & & T2-entre $R \$ 250,00$ e $R \$ 500,00$ & \\
\hline & & & & $\mathrm{T} 3-\geq 500,00$ & \\
\hline & \multirow{4}{*}{ Ind.08 } & \multirow{4}{*}{$\begin{array}{l}\text { Percentual de autofinanciamento da coleta } \\
\text { seletiva-\% }\end{array}$} & \multirow{4}{*}{$\begin{array}{l}\text { (custo total da coleta seletiva incluindo } \\
\text { triagem)/(arrecadação da taxa de lixo ou } \\
\text { recurso do IPTU e preço público cobrado de } \\
\text { grandes geradores)×100 }\end{array}$} & T1-75 a $100 \%$ & \\
\hline & & & & T2-50,1 a $74,9 \%$ & \\
\hline & & & & T3-25 a $49,9 \%$ & \\
\hline & & & & $\mathrm{T} 4-<25 \%$ & \\
\hline & \multirow{3}{*}{ Ind.09 } & \multirow{3}{*}{$\begin{array}{l}\text { Custo da coleta seletiva em relação à coleta } \\
\text { regular e disposição final adequada-\% }\end{array}$} & \multirow{3}{*}{$\begin{array}{l}\text { (custo total com coleta seletiva)/(custo da } \\
\text { coleta regular e disposição final } \\
\text { adequada) } \times 100\end{array}$} & $\mathrm{~T} 1-\leq 50 \%$ & \\
\hline & & & & T2-50,1 a $199,9 \%$ & \\
\hline & & & & T3- $\geq 200 \%$ & \\
\hline & \multirow{4}{*}{ Ind.10 } & \multirow{4}{*}{$\begin{array}{c}\text { Custo da coleta seletiva em relação aos } \\
\text { custos com limpeza urbana e manejo de } \\
\text { resíduos-\% }\end{array}$} & \multirow{4}{*}{$\begin{array}{l}\text { (custo total com coleta seletiva)/(custo com } \\
\text { limpeza urbana e manejo de resíduos } \\
\text { sólidos) } \times 100\end{array}$} & $\mathrm{~T} 1-\leq 25 \%$ & \\
\hline & & & & $\mathrm{T} 2-25,1$ a $50 \%$ & \\
\hline & & & & $\mathrm{T} 3-\leq 50,1$ a $74,9 \%$ & \\
\hline & & & & T3- $\geq 75 \%$ & \\
\hline & \multirow{3}{*}{ Ind.13 } & \multirow{3}{*}{$\begin{array}{l}\text { Aplicação dos recursos financeiros } \\
\text { provenientes da coleta seletiva }\end{array}$} & \multirow{3}{*}{$\begin{array}{c}\text { forma de aplicação dos recursos financeiros } \\
\text { provenientes da coleta seletiva }\end{array}$} & $\begin{array}{r}\text { T1-na própria manutenção da coleta } \\
\text { seletiva }\end{array}$ & \\
\hline & & & & $\begin{array}{r}\text { T2-atividades socioculturais e } \\
\text { assistenciais } \\
\end{array}$ & \\
\hline & & & & $\begin{array}{r}\text { T3-outra destinação (saúde, educação e } \\
\text { prevenção de acidentes) }\end{array}$ & \\
\hline
\end{tabular}

FONTE: Fechine (2014).

\begin{tabular}{|c|c|c|c|c|c|}
\hline \multicolumn{3}{|c|}{ INDICADORES E DIMENSÕES DA SUSTENTABILIDADE } & FORMA DE APURAÇÃO & TENDÊNCIA À SUSTENTABILIDADE & NOTA \\
\hline \multirow{17}{*}{ 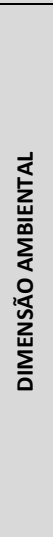 } & \multirow{3}{*}{ Ind.14 } & \multirow{3}{*}{$\begin{array}{l}\text { Massa per capita anual recuperada - } \\
\qquad \mathrm{kg} / \mathrm{hab}\end{array}$} & \multirow{3}{*}{$\begin{array}{l}\text { (massa total de materiais recicláveis } \\
\text { recuperados)/(população urbana) }\end{array}$} & T1->15kg/hab.ano & \\
\hline & & & & T2-7 a 15kg/hab.ano & \\
\hline & & & & T3-<7kg/hab.ano & \\
\hline & \multirow{3}{*}{ Ind.15 } & \multirow{3}{*}{$\begin{array}{c}\text { Massa per capita coletada seletivamente - } \\
\text { kg/hab.ano }\end{array}$} & \multirow{3}{*}{$\begin{array}{l}\text { (quantidade total recolhida pela coleta } \\
\text { seletiva)/(população urbana) }\end{array}$} & T1->21kg/hab.ano & \\
\hline & & & & T2-10 a 21kg/hab.ano & \\
\hline & & & & T3-<10kg/hab.ano & \\
\hline & \multirow{3}{*}{ Ind.16 } & \multirow{3}{*}{ Taxa de rejeitos - \% } & \multirow{3}{*}{$\begin{array}{l}\text { (massa coletada seletivamente - massa } \\
\text { recuperada)/(quantidade da coleta } \\
\text { seletiva) } \times 100\end{array}$} & $\mathrm{~T} 1-\leq 10 \%$ & \\
\hline & & & & T2-10,1 a $19,9 \%$ & \\
\hline & & & & $\mathrm{T} 3-\geq 20 \%$ & \\
\hline & \multirow{4}{*}{ Ind.17 } & \multirow{4}{*}{$\begin{array}{l}\text { Taxa de material recolhido nos PEVs em } \\
\text { relação a massa coletada seletivamente - \% }\end{array}$} & \multirow{4}{*}{$\begin{array}{l}\text { (massa recolhida nos PEVs)/(quantidade } \\
\text { coletada seletivamente) } \times 100\end{array}$} & $\mathrm{~T} 1->40 \%$ & \\
\hline & & & & $\mathrm{T} 2-20$ a $40 \%$ & \\
\hline & & & & T3-<20\% & \\
\hline & & & & T4-não possui PEVs ou desativados & \\
\hline & \multirow{3}{*}{ Ind.18 } & \multirow{3}{*}{$\begin{array}{l}\text { Taxa de recuperação de materiais } \\
\text { recicláveis em relação à quantidade total } \\
\text { (RDO+RPU) coletada - \% } \\
\end{array}$} & \multirow{3}{*}{$\begin{array}{c}\text { (massa coletada seletivamente }- \text { massa de } \\
\text { rejeitos)/(massa coletada seletivamente } \\
\text { +massa de coleta regular) } \times 100\end{array}$} & $\mathrm{~T} 1->11 \%$ & \\
\hline & & & & $\mathrm{T} 2-5,1$ a $10 \%$ & \\
\hline & & & & T3-até 5\% & \\
\hline & & 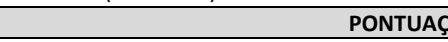 & XIMA PARA A DIMENSÃO ECONÔMICA & & \\
\hline
\end{tabular}

FONTE: Fechine (2014).

\begin{tabular}{|c|c|c|c|c|c|}
\hline \multicolumn{3}{|c|}{ INDICADORES E DIMENSÕES DA SUSTENTABILIDADE } & FORMA DE APURAÇÃO & TENDÊNCIA À SUSTENTABILIDADE & NOTA \\
\hline \multirow{19}{*}{ 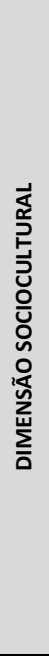 } & \multirow{3}{*}{ Ind.19 } & \multirow{3}{*}{ Adesão da população - \% } & \multirow{3}{*}{$\begin{array}{c}\text { ( } \mathrm{n} \text { - de residências que participa do } \\
\text { programa)/(no de residências atendidas pelo } \\
\text { programa) } \times 100\end{array}$} & $\mathrm{~T} 1->80 \%$ & \\
\hline & & & & T2-40,1 a 79,9\% & \\
\hline & & & & $\mathrm{T} 3-\leq 40 \%$ & \\
\hline & \multirow{3}{*}{ Ind.20 } & \multirow{3}{*}{ Programas de educação e divulgação } & \multirow{3}{*}{ frequencia das atividades desenvolvidas } & T1-permanente, quinzenal, mensal & \\
\hline & & & & T2-bi ou trimestral & \\
\hline & & & & T3-anual ou esporádica & \\
\hline & \multirow{3}{*}{ Ind.21 } & \multirow{3}{*}{ Inclusão de catadores avulsos - \% } & \multirow{3}{*}{$\begin{array}{l}\text { (no de catadores avulsos incluídos no } \\
\text { programa de coleta seletiva)/(no total de } \\
\text { catadores avulsos existentes) } \times 100 \\
\end{array}$} & T1-80 a $100 \%$ & \\
\hline & & & & T2-50,1 a $79,9 \%$ & \\
\hline & & & & $\mathrm{T} 3-\leq 50 \%$ & \\
\hline & \multirow{3}{*}{ Ind.22 } & \multirow{3}{*}{ Renda média mensal nas cooperativas - $\mathrm{R} \$$} & \multirow{3}{*}{$\begin{array}{l}\text { valor médio pago aos catadores organizados } \\
\text { em cooperativas }\end{array}$} & T1-Acima de 1 salário mínimo(SM) & \\
\hline & & & & T2-Entre 0,5 e 1SM & \\
\hline & & & & T3-<0,5SM & \\
\hline & \multirow{3}{*}{ Ind.23 } & \multirow{3}{*}{$\begin{array}{l}\text { Participação de catadores nas ações de } \\
\text { coleta seletiva }\end{array}$} & \multirow{3}{*}{$\begin{array}{l}\text { forma de participação dos catadores nas } \\
\text { ações de coleta seletiva }\end{array}$} & $\begin{array}{r}\text { T1-organizados em cooperativas ou } \\
\text { associações }\end{array}$ & \\
\hline & & & & T2-isolada (individual) & \\
\hline & & & & $\begin{array}{l}\text { T3-outra (grupos de tamanhos } \\
\text { diversos, mas sem associação) }\end{array}$ & \\
\hline & \multirow{3}{*}{ Ind.24 } & \multirow{3}{*}{$\begin{array}{c}\text { Existência de cooperativas ou associações } \\
\text { no município - coop./hab. }\end{array}$} & \multirow{3}{*}{$\begin{array}{l}\text { no de cooperativas ou associações de } \\
\text { catadores } / 10^{6}\end{array}$} & T1->35 & \\
\hline & & & & T2-entre 15 e 34 & \\
\hline & & & & $\mathrm{T} 3-<15$ & \\
\hline & \multicolumn{4}{|c|}{ PONTUAÇÃO MÁXIMA PARA A DIMENSÃO SOCIOCULTURAL } & \\
\hline
\end{tabular}

FONTE: Fechine (2014). 


\section{CONSIDERAÇÕES FINAIS}

Ao longo da pesquisa foi possível identificar os indicadores de coleta seletiva mais expressivos no Brasil. Partiu-se do princípio que uma coleta seletiva sustentável abrangeria as dimensões institucional/operacional, econômica, ambiental e sociocultural, o que permitiria uma visão sistêmica.

Após a revisão bibliográfica, foi possível observar que a geração de indicadores de coleta seletiva, de uma forma geral, aumentou no Brasil, porém a implementação destes indicadores não tem acompanhado esse aumento. Sobram obstáculos para o seu uso efetivo, entre eles o fato de que os programas de coleta seletiva são concebidos para um horizonte de curto prazo devido, principalmente, às inconstâncias administrativas pelas quais os municípios passam.

Com relação ao processo de construção da matriz de indicadores de sustentabilidade de coleta seletiva pode-se concluir que os procedimentos e técnicas utilizados na pesquisa foram adequados e permitiram alcançar os objetivos propostos. O método Delphi obteve uma boa adesão alcançando $60,5 \%$ e $96,2 \%$ na primeira e segunda rodada, respectivamente, sendo o número de participantes considerado suficiente para a obtenção de dados confiáveis, já que estes atuam em diversas áreas (acadêmica, técnica e operacional). A avaliação dos especialistas contribuiu para um maior detalhamento e aprimoramento dos indicadores de sustentabilidade de coleta seletiva.

Vale ressaltar que 0 trabalho com indicadores deve ser monitorizado e seus valores de referência devem ser constantemente atualizados e adaptados às especificidades de cada região para garantir a sua aplicabilidade. $O$ grande desafio é manter o sistema de indicadores atualizado, face a grande fragilidade técnicooperacional e econômica das prefeituras.

De forma geral, o método Delphi demonstrou ser uma importante ferramenta para a busca de consenso entre especialistas de uma mesma área de conhecimento. O conjunto de indicadores de sustentabilidade é representativo e a matriz resultante da aplicação do método Delphi poderá ser aplicada a realidades distintas e utilizada como instrumento de avaliação e planejamento das ações de coleta seletiva, permitindo uma visão sistêmica que considera as diferentes dimensões da sustentabilidade. Com esta ferramenta, além dos gestores públicos poderem planejar e monitorizar os programas de coleta seletiva, a sociedade poderá ter informações e avaliar os serviços prestados.

Dessa forma, recomenda-se a disseminação desses indicadores, aprofundando o seu conceito como ferramenta de gestão e a aplicação da matriz em programas de coleta seletiva implantados nas cidades brasileiras, o que permitirá também uma análise comparativa entre tais programas.

\section{REFERÊNCIAS BIBLIOGRÁFICAS}

BESEN, G. R. (2011). Coleta seletiva com inclusão de catadores: construção participativa de indicadores e índices de sustentabilidade. 274f. Tese (Doutorado em Saúde Pública) - Faculdade de Saúde Pública, Universidade de São Paulo, São Paulo, 2011.

BRASIL. Lei no 12.305, de 02 de agosto de 2010. Institui a Política Nacional de Resíduos Sólidos, 2010. Disponível em: http://www.presidencia.gov.br Acesso em: 10 setembro de 2012.

FECHINE, R. (2014). Indicadores de Sustentabilidade como Instrumentos para Avaliação de Programas de Coleta Seletiva na Cidade de Salvador-BA. $149 f$. Dissertação (Mestrado em Meio Ambiente, Águas e Saneamento) - Escola Politécnica, Universidade Federal da Bahia, Salvador - BA, 2014.

IBGE - Instituto Brasileiro de Geografia e Estatística. Pesquisa Nacional do Saneamento Básico 2008. Rio de Janeiro: IBGE, 2010. Disponível em: http://www.ibge.gov.br. Acesso em: 20 out. 2011

IPEA - Instituto de Pesquisa Econômica Aplicada. Comunicado $N^{\circ}$ 145: Plano Nacional de Resíduos Sólidos - diagnóstico dos resíduos urbanos, agrosilvopastoris e a questão dos catadores. Brasília, 2012. Disponível em: http://www.ipea.gov.br. Acesso em: 13 de maio de 2012. 
LOZANO, M.C. Um olhar para a gestão de resíduos sólidos urbanos a partir de indicadores de sustentabilidade. 2012. 100f. Dissertação (Mestrado em Engenharia Urbana) - Universidade Federal de São Carlos, São Carlos, 2012. Disponível em: http://www.bdtd.ufscar.br/htdocs/tedeSimplificado/td e_arquivos/11/TDE-2012-09-20T150812Z-

4632/Publico/4518.pdf. Acesso em: 29 janeiro de 2013.

MINAYO, M. C. de S. Construção de indicadores qualitativos para avaliação de mudanças. Revista Brasileira de Educação Médica, v. 33, Supl.1, p. 83-91, 2009.

RIBEIRO, H.; JACOBI, P.R.; BESEN, G.R.; GÜNTHER, W.M.R.; DEMAJOROVIC, J.; VIVEIROS, M. Coleta Seletiva com inclusão social: cooperativismo e sustentabilidade. 1.ed. São Paulo: Annablume, 2009. 112p. (Coleção Cidadania e Meio Ambiente).

SANTIAGO, L.S; DIAS, S.M.F. Matriz de indicadores de sustentabilidade para a gestão de resíduos sólidos urbanos. Revista Eng Sanit Ambient. v.17, n.2. p. 203212. Abr-jun. 2012. Disponível em: http://www.scielo.br/pdf/esa/v17n2/a10v17n2.pdf.. Acesso: 12 de março de 2013.

SANTIAGO, L. S. Construção de uma matriz de indicadores de sustentabilidade para a gestão de resíduos sólidos urbanos. 2011. 129f. Dissertação (Mestrado em Ciências em Engenharia Civil e Ambiental) - Universidade Estadual de Feira de Santana, Feira de Santana, 2011.

SCARPARO, A.F; LAUS, A.M; AZEVEDO, A.L.C.S; FREITAS, M.R.I; GABRIEL, C.S; CHAVES, L.D.P. Reflexões sobre o uso da técnica Delphi em pesquisas na enfermagem. Revista Rene, v.13, n.1, p.242-251. 2012. Disponível em: www.revistarene.ufc.br/revista/index.php/revista/articl e/download/.../31. Acesso em: 22 de junho de 2013.

WRIGHT, J.T.C; GIOVINAZZO, R.A. Delphi - Uma ferramenta de apoio ao planejamento prospectivo. Caderno de Pesquisas em Administração, São Paulo, v. 01, n. 12, 2000. Disponível em: www.cgee.org.br/atividades/redirKori/861. Acesso: 24 de janeiro de 2013. 